\title{
Chronic Venous Leg Ulcer in Klinefelter Syndrome Treated with Platelet-Rich Fibrin: A Case Report
}

\author{
Eva Krishna Sutedja (iD \\ Retno Hesty Maharani (D) \\ Unwati Sugiri \\ Pati Aji Achdiat (D) \\ Department of Dermatology and \\ Venereology, Faculty of Medicine, \\ Universitas Padjadjaran - Dr. Hasan \\ Sadikin General Hospital, Bandung, \\ Indonesia
}

\begin{abstract}
Venous leg ulcers (VLUs) are the most common causes of leg ulcers due to venous insufficiency. Most cases persist for more than 6 weeks, referred to as chronic VLUs. These chronic ulcers have been described as a manifestation of Klinefelter syndrome (KS). Platelet-rich fibrin (PRF) is a second-generation platelet concentrate, which contains growth factors required for chronic wound healing. The use of PRF in the management of VLUs in KS has not been reported, to the best of our knowledge. We report a case of chronic VLU associated with KS in a 41-year-old man treated with PRF. Dermatological examination showed a tender, shallow, irregular ulcer partly covered with hard, yellow necrotic tissue on the anterior side of the lower-left leg and hyperpigmented indurated skin on both lower legs. The diagnosis of venous ulcer was established based on clinical manifestation and supported by the result of Doppler ultrasound showed chronic venous insufficiency. Histopathological examination, which showed epidermal acanthosis, dermal fibrosis, and thickening with hemosiderin deposits consistent with the diagnosis of venous ulcer. The patient presented with eunuchoid features characterized by long extremities, gynecomastia, increased fat distribution around the hips, scanty pubic hairs, and small testes. Laboratory tests found decreased levels of testosterone, increased levels of follicle-stimulating and luteinizing hormone, and bilateral testicular atrophy was found from testicular ultrasound. These physical examinations and laboratory findings supported the diagnosis of KS. The patient was treated with PRF dressing once a week. After 7 weeks of treatment with PRF, the ulcer almost reached complete closure. PRF gives a good result in a chronic VLU with KS.
\end{abstract}

Keywords: Klinefelter syndrome, platelet-rich fibrin venous leg ulcers

\section{Introduction}

Venous leg ulcer (VLU) is a severe clinical manifestation of chronic venous insufficiency (CVI) on the lower legs. ${ }^{1,2}$ The ulcers are typically shallow, irregular with well-defined borders, and surrounded by erythematous or hyperpigmented indurated skin. ${ }^{1}$ On average, $70 \%$ of these ulcers persist for more than six weeks, referred to as chronic VLUs. ${ }^{1}$ Recurrent VLUs are possibly associated with abnormalities of chromosomes such as Klinefelter syndrome (KS). ${ }^{3}$ To date, the percentage of VLUs in KS is still not exactly known. ${ }^{4}$ The phenotype of KS is characterized by eunuchoid body proportions with long lower extremities, gynecomastia, scanty secondary sexual hairs, small testes, and leg ulcers. ${ }^{5}$ Platelet-rich fibrin (PRF) is a second-generation platelet concentrate that contains white blood cells (WBC) and growth factors (GF) in a natural fibrin matrix that are important in
Correspondence: Eva Krishna Sutedja Department of Dermatology and Venereology, Faculty of Medicine, Universitas Padjadjaran - Dr. Hasan Sadikin General Hospital, Jl. Pasteur No. 38, Bandung, West Java, 40I6I, Indonesia

Tel +62222032426 ext. 3449

Fax +62222032426

Email evakrishna@yahoo.com 
tissue regeneration and wound healing. ${ }^{6}$ Recently, PRF has been used for the management of hard-to-heal leg ulcers, including VLUs and other chronic ulcers. ${ }^{6}$ Here, we report a case of chronic VLU associated with KS in a 41-year-old man treated with PRF.

\section{Case}

A 41-year-old widower man presented with a 1-year history of an ulcer on the left leg. He first noted small genitalia and changes at the breasts at age 20 . The patient was a smoker, worked as a farmer with prolonged periods of standing, had a positive family history of varicose veins, and had been married twice but had no children.
Physical examination revealed obesity (height: $175 \mathrm{~cm}$, weight: $97 \mathrm{~kg}$, body-mass index: $31.7 \mathrm{~kg} / \mathrm{m}^{2}$ ), eunuchoid body proportion, gynecomastia, increased fat distribution around the hip and thighs, scanty pubic hairs, and small testes [Figure $1 \mathrm{~A}$ and $\mathrm{B}$ ]. The size of the penis was $3 \mathrm{~cm}$ in length with Tanner stage 3 pubic hair. Both of his lower legs showed varicose veins [Figure $1 \mathrm{D}$ and E]. A $5 \times 4$ $\mathrm{x} 0.3 \mathrm{~cm}$ shallow ulcer with irregular borders on the anterior side of the lower-left leg was observed [Figure 1C]. The ulcer had granulation tissue at the base of the wound and was partly covered with hard, yellow necrotic tissue. There were also atrophie blanche and hyperpigmented indurated skin on both lower legs.
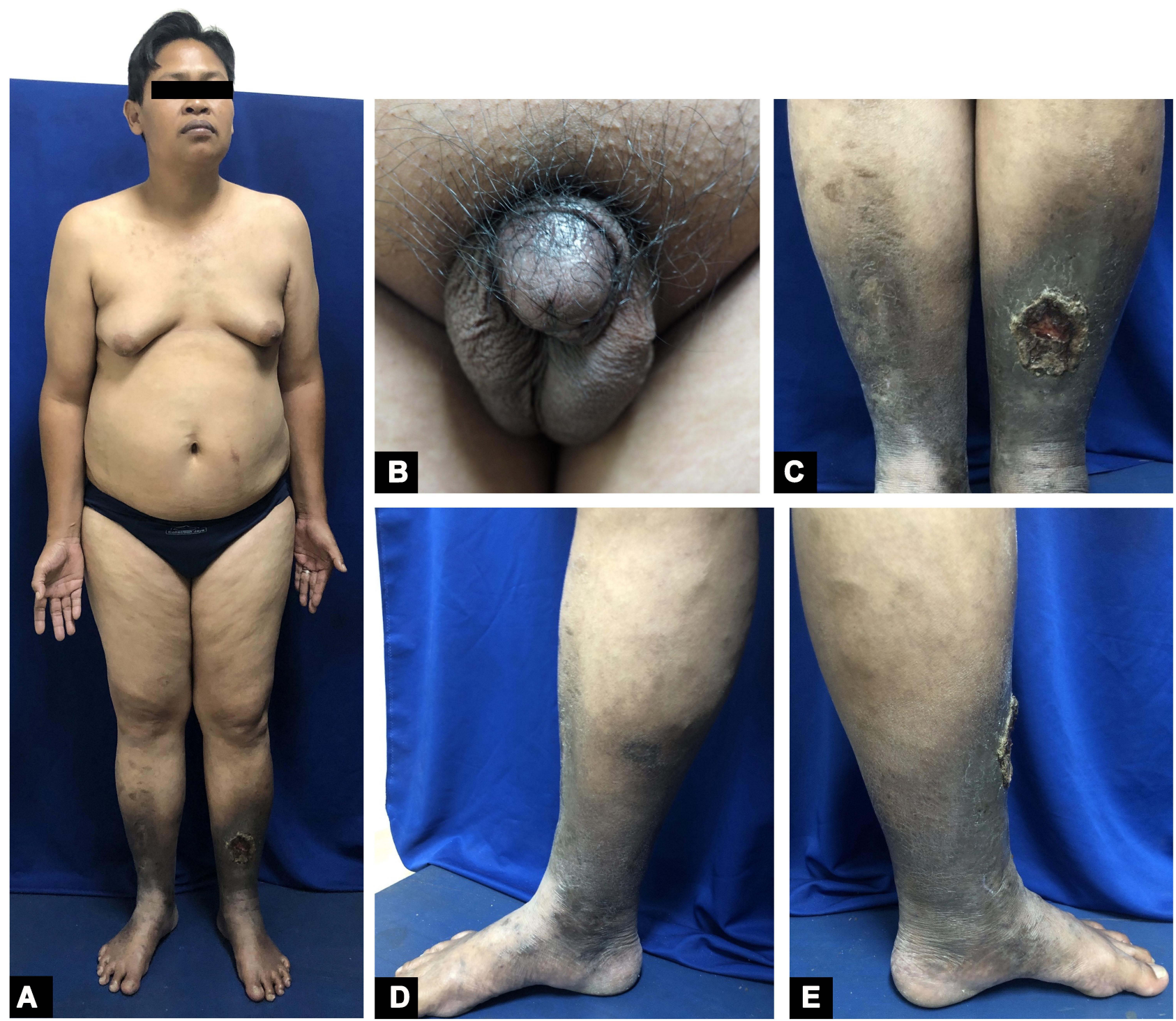

Figure I Physical examination showing eunuchoid body proportions, obesity, long extremities, gynecomastia, scanty pubic hairs, small testes (A and B). Shallow ulcer with yellow necrotic tissue on the lower-left leg and atrophie blanche on both lower legs (C). Varicose veins with hyperpigmented indurated skin appear on both lower legs (D and $\mathbf{E})$. 
Venous Doppler ultrasound suggested CVI on the great saphenous vein and small saphenous vein (SSV) of the right leg and SSV of the left leg. Testicular ultrasound showed bilateral testicular atrophy with size $\pm 1.94 \times 1.08$ $\mathrm{x} 0.64 \mathrm{~cm}$ (volume $\pm 0.7 \mathrm{~mL}$ ) and $\pm 1.11 \times 1.34 \times 0.75 \mathrm{~cm}$ (volume $\pm 0.58 \mathrm{~mL}$ ) on the right and left testes, respectively. Hormonal examinations revealed a low serum testosterone level of $40.29 \mathrm{ng} / \mathrm{dL}$ (normal range for men 249 $836 \mathrm{ng} / \mathrm{dL}$ ), elevated level of follicle-stimulating hormone (FSH) $52.19 \mathrm{IU} / \mathrm{mL}$ (normal range for men 1.4-18.1 IU/ $\mathrm{mL}$ ), and luteinizing hormone $(\mathrm{LH}) 52.19 \mathrm{IU} / \mathrm{mL}$ (normal range for men 1.5-9.3 IU/mL). Histopathological examination of the ulcer margin revealed epidermal acanthosis, dermal fibrosis, and thickening, with hemosiderin deposits [Figure 2]. Diagnosis of chronic VLU with KS was made. The patient had been unresponsive to 6 weeks of dressings using saline with Vaseline gauze, Hydrofiber dressings, and compression bandage. Therefore, a topical treatment using autologous PRF every week was chosen for the patient. Forty $\mathrm{mL}$ of autologous venous blood was collected in four plain vacutainer tubes without any anticoagulants and immediately centrifuged the blood at 3000 rotations per minute for 15 minutes. Fibrin clots that appeared in the center of the vacutainer (in between acellular plasma and the red blood cells) after 15 minutes were applied to the ulcer [Figure $3 \mathrm{~A}-\mathrm{C}$ ]. The ulcer was covered with sterile gauze. At each weekly visit, the old dressing was replaced with a new PRF dressing. Clinical improvement was measured every week. The mean reduction area of the ulcer was $43.75 \%$ after 2 weeks, $70 \%$ after 4 weeks [Figure 3D], and after 7 weeks $99.9 \%$ of the ulcer had closed [Figure 3E]. The patient was advised to use compression therapy to prevent the recurrence of VLU.

\section{Discussion}

Venous leg ulcers are the most common form of ulcers on the lower extremities with a prevalence of $0.1 \%$ and the incidence has increased to $4 \%$ in the over- 80 population. ${ }^{1,2}$ In general, the ulcers were superficial, irregularly shaped with a red base, and surrounded by erythematous or hyperpigmented induration of skin. ${ }^{1}$ The diagnosis of VLU is mostly clinical. ${ }^{1}$ Supporting examination such as a biopsy can be considered in chronic ulcers to exclude malignancies. ${ }^{1}$

Klinefelter syndrome is a rare, nonhereditary disorder of the sex chromosomes affecting one in 500-1000 male births. $^{5,7}$ The phenotype is classically characterized by a eunuchoid body, long lower extremities, gynecomastia, sparse body hairs, broad hips, and small testes. ${ }^{7}$ Other abnormal findings are testicular atrophy, azoospermia, infertility, behavioral disorders, and reduced intelligence. ${ }^{7}$ People with KS have an increased risk of developing VLU, deep venous thrombosis, and pulmonary embolism related to a defect of the basement membrane in the venous valve or underlying hypercoagulable state. ${ }^{8}$ A dermatologist should be aware that recurrent leg ulcerations may be a clinical presentation of $\mathrm{KS}^{3}$
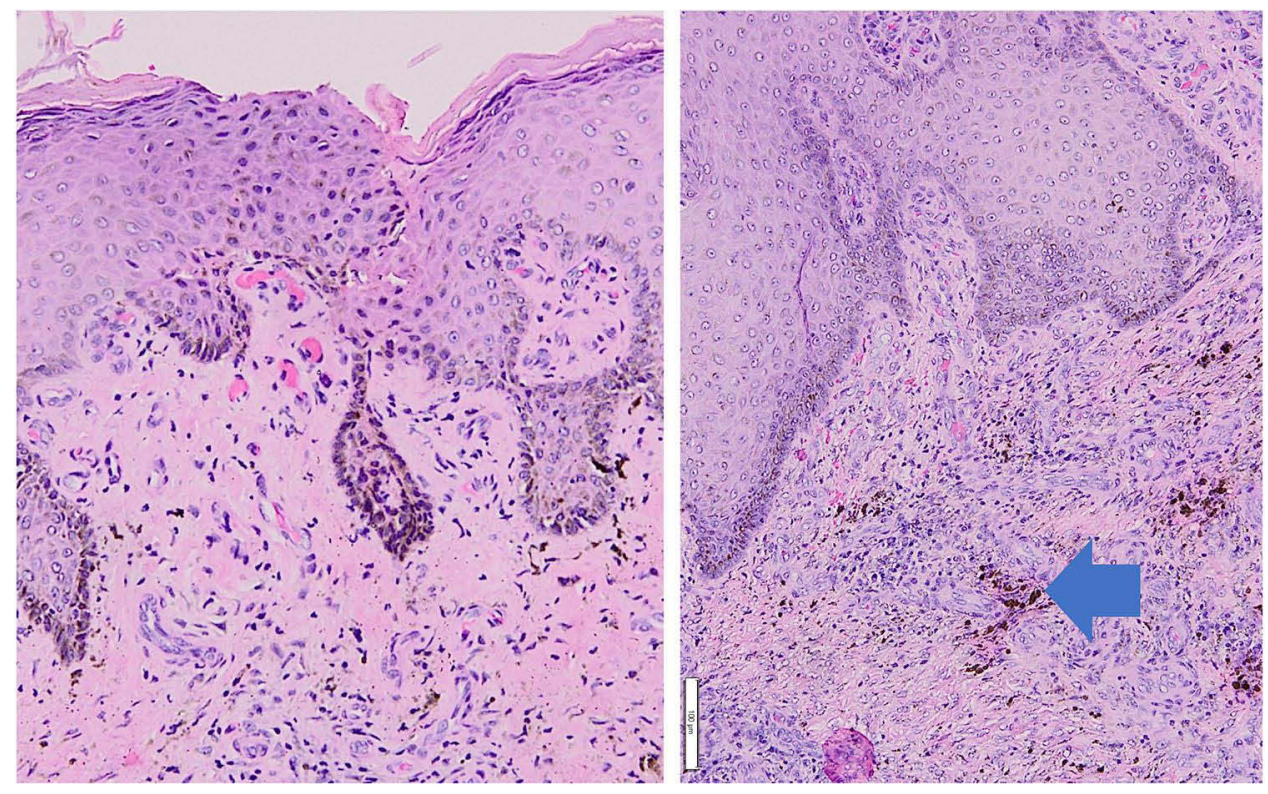

Figure 2 Histopathological findings (Hematoxylin and eosin; $x 100$ and $\times 200$ magnifications) showed epidermal acanthosis, dermal fibrosis, and thickening, hemosiderin deposits (blue arrow). 

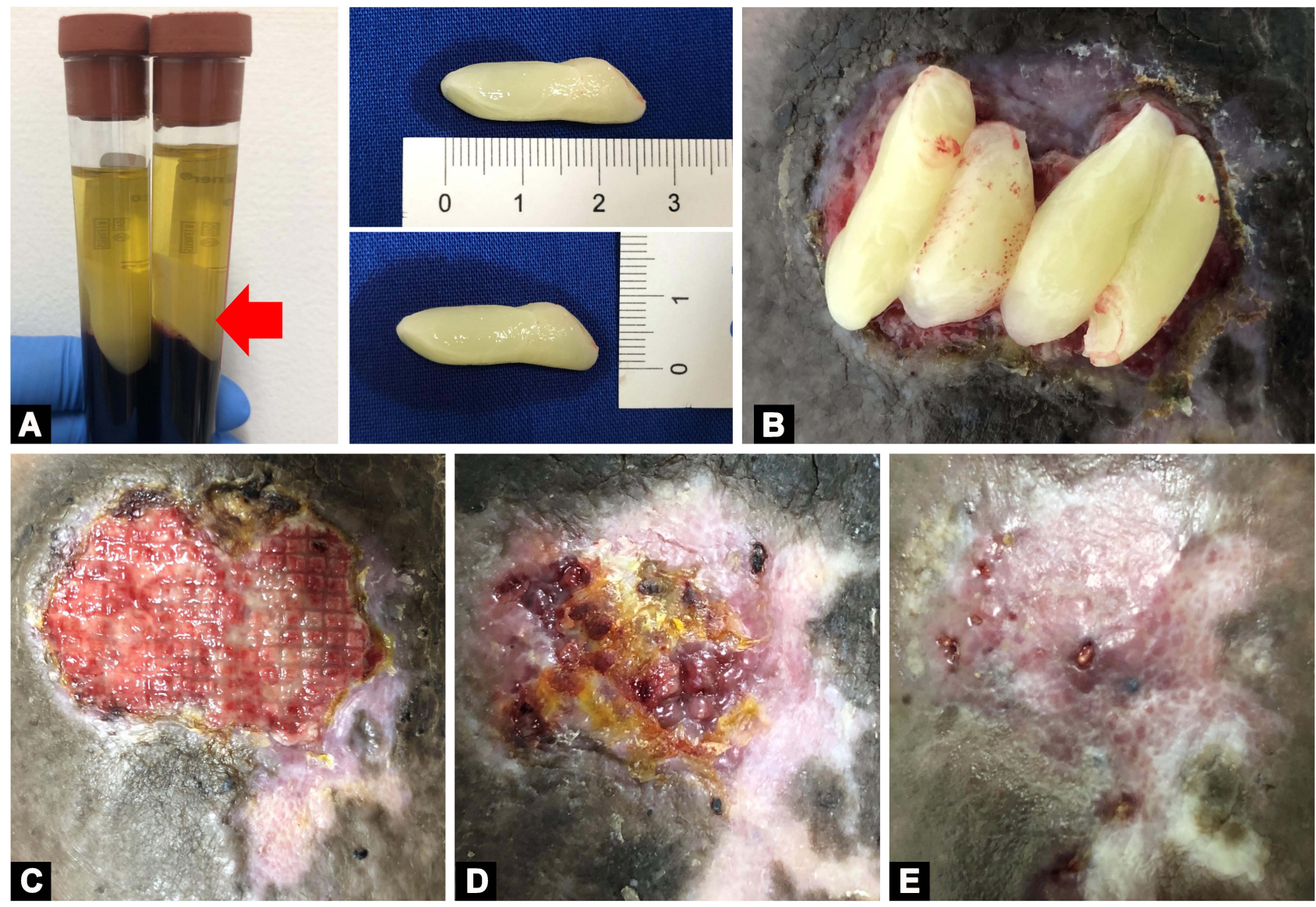

Figure 3 Fibrin clot at the center of vacutainer (red arrow) (A). Four PRF clots were placed in the entire ulcer area (B). Clinical manifestation of venous leg ulcer before (C), after 4 weeks (D), and after 7 weeks of PRF dressing (E).

The etiopathogenesis of leg ulcers in KS is multifactorial, influenced by the presence of CVI, obesity, decrease in fibrinolysis due to elevated levels of plasminogen activator inhibitor type 1 (PAI-1), and arterial dysplasia on the legs. ${ }^{5}$ PAI-1 inhibits fibrinolysis and promotes thrombosis by inhibiting tissue plasminogen and urokinase plasminogen activator. ${ }^{9}$ Zollner et al $^{10}$ reported higher activity of PAI-1 in the group of KS with leg ulcers compared to KS only. Metabolic syndrome such as diabetes, arterial hypertension, hypertriglyceridemia, obesity, and smoking was contributed to the elevation of PAI-1 activity. ${ }^{9}$ In this report, the patient developed a shallow, exudative, granulation-based ulcer, with irregular borders on the left lower leg. There were atrophie blanche, hyperpigmented indurated skin, and varicose veins on both lower legs. Doppler ultrasound suggested CVI. Hence, the diagnosis of VLU was established. Histopathological examination revealed epidermal acanthosis, dermal fibrosis, and thickening, with hemosiderin deposits, that are consistent with the diagnosis of venous ulcer. Because of the patient's eunuchoid body proportions, gynecomastia, small penis, and testes, we suspected Klinefelter syndrome, supported by the results of the testicular ultrasound, reduced testosterone levels of more than $50 \%$, abnormalities of FSH and LH, despite no chromosomal analysis. We also did not perform PAI-1 due to limited laboratory capacity.

Treatment of VLUs in patients with chromosomal anomalies involves the same management as in other patients. ${ }^{11}$ The treatment of VLUs consisted of measures to reduce the effects of venous hypertension (compression therapy, surgical treatment for venous abnormality), local treatment for the ulcer, systemic drugs, and complementary measures (leg elevated above the level of the heart, short walks). ${ }^{12}$ Compression therapy remains as the first-line and standard treatment for VLUs, which in turn improves venous hemodynamics by applying external pressure to the ankle around $35-40 \mathrm{mmHg} .{ }^{12}$ The lifelong maintenance of compression therapy is necessary to decrease the risk of ulcer recurrence. ${ }^{13}$ Meanwhile, for cases of VLUs associated with $\mathrm{KS}$, there is no 
established therapy. ${ }^{7}$ Some studies suggested androgen replacement therapy can normalize the low testosterone level and reduce PAI-1 levels, therefore encouraging improvement of leg ulcers. ${ }^{5,9}$ PRF is a secondgeneration platelet concentrate, containing more WBC than the platelet-rich plasma and has 6-8 times concentration of GF compared to whole blood. ${ }^{6}$ It is easy to prepare, low cost, and effective as a promising therapy for chronic ulcers such as VLUs that do not respond well to standard treatment within four weeks characterized by no significant wound reduction $(30-50 \%) .{ }^{14}$ In vitro, membranes of PRF progressively release significant GF such as transforming growth factor $\beta 1$, platelet-derived growth factor $\mathrm{AB}$, vascular endothelial growth factors, insulin-like growth factors, matrix glycoproteins, and cytokines within 7 days. ${ }^{14}$ These GF together with neutrophils and platelets facilitate tissue regeneration, angiogenesis, and prevention of infection which are important in wound healing. ${ }^{6}$ Somani et $\mathrm{al}^{15}$ concluded that patients who were treated with PRF dressings tend to heal faster than saline dressings. The study consisted of 15 patients with $1 \times 1 \mathrm{~cm}$ to $5 \times 5 \mathrm{~cm}$ area of chronic VLUs (more than 6 months), divided into two groups. The first group received a PRF dressing once a week, compared to the second group which received a saline dressing once a week. After 4 weeks, the mean reduction area of each group was $85.51 \%$ and $42.74 \%$, respectively. ${ }^{15} \mathrm{O}^{\prime}$ Connell et $\mathrm{al}^{16}$ reported complete closure in $66.7 \%$ of VLU patients in 7.1 weeks. Another study conducted by Pinto et al, ${ }^{14}$ which included 44 patients with refractory leg ulcers, reported complete closure of all VLUs $\leq 10 \mathrm{~cm}^{2}$, diabetic foot ulcers, and complex wounds within 9 weeks of PRF therapy. In this case, the patient initially received conventional therapy consisting of dressings with saline with Vaseline gauze, Hydrofiber dressings, and compression bandage. After 6 weeks, due to minimal response of wound healing, the therapy was changed to PRF. After 4 weeks of PRF therapy, the mean reduction area of the VLU was $70 \%$, and after 7 weeks the ulcer had almost closed completely (99.9\%). Based on this finding, PRF gives a good response in this present case.

\section{Conclusion}

Recurrent VLUs are possibly associated with chromosomal abnormalities such as KS. Here, we report on the treatment of KS-associated VLU using PRF with a good therapeutic response. To the best of our knowledge, management of chronic VLUs in KS using PRF has not been reported.

\section{Ethic Statement}

The publications of images were included in the patient's consent for publication of the case. Institutional approval has been obtained to publish the case details (approval number: LB.02.01/X.6.5/344/2020).

\section{Consent Statement}

The authors certify that they have obtained all appropriate patient consent forms. The patient signed a consent form for the publication of the case details and images.

\section{Acknowledgments}

The authors would like to thank the staff of the Department of Dermatology and Venereology, Faculty of Medicine, Universitas Padjadjaran, Bandung, West Java, Indonesia.

\section{Disclosure}

The authors report no conflicts of interest in this work.

\section{References}

1. Abbade LF, Lastória S. Venous ulcer: epidemiology, physiopathology, diagnosis, and treatment. Int J Dermatol. 2005;44(6):449-456. doi:10.1111/j.1365-4632.2004.02456.x

2. Hafner J. Ulceration resulting from disorders of the veins and arteries. In: Griffiths CE, Barker J, Bleiker T, Chaimers R, Creamer D, editors. Rook's Textbook of Dermatology. 9th ed. West Sussex: Willey Blackwell; 2016:104.1-104.14.

3. Spier C, Shear NH, Lester RS. Recurrent leg ulcerations as the initial clinical manifestation of Klinefelter's syndrome. Arch Dermatol. 1995;131(2):230. doi:10.1001/archderm.131.2.230

4. Veraart JC, Hamulyak K, Neumann HA. Leg ulcers and Klinefelter's syndrome. Arch Dermatol. 1995;131(8):958-959. doi:10.1001/archderm.131.8.958

5. De-morentin HM, Dodiuk-Gad RP, Brenner S. Klinefelter's syndrome presenting with leg ulcers. Skinmed. 2004;3(5):274-278.

6. Miron RJ, Fujioka-Kobayashi M, Bishara M, Zhang Y, Hernandez M, Choukroun J. Platelet-rich fibrin and soft tissue wound healing: a systematic review. Tissue Eng Part B Rev. 2017;23(1):83-99. doi:10.1089/ten.teb.2016.0233

7. Yabuno Y, Tosa M, Iwakiri I, et al. Refractory leg ulcers associated with Klinefelter syndrome. J Nippon Med Sch. 2015;82(1):64-67. doi:10.1272/jnms.82.64

8. Smyth CM, Bremner WJ. Klinefelter syndrome. Arch Intern Med. 1998;158(12):1309-1314. doi:10.1001/archinte.158.12.1309

9. Shanmugam VK, Tsagaris KC, Attinger CE. Leg ulcers associated with Klinefelter's syndrome: a case report and review of the literature. Int Wound J. 2012;9(1):104-107. doi:10.1111/j.1742-481X.20 11.00846.x

10. Zollner TM, Veraart JC, Wolter M, et al. Leg ulcers in Klinefelter's syndrome - further evidence for an involvement of plasminogen activator inhibitor-1. Br J Dermatol. 1997;136(3):341-344. 
11. Gattringer C, Scheurecker C, HöPFl R, MüllER H. Association between venous leg ulcers and sex chromosome anomalies in men. Acta Derm Venereol. 2010;90(6):612-615.

12. Abbade LP, Frade MA, Pegas JR, et al. Consensus on the diagnosis and management of chronic leg ulcers-Brazilian Society of Dermatology. An Bras Dermatol. 2021;95:1-8.

13. Latz CA, Brown KR, Bush RL. Compression therapies for chronic venous leg ulcers: interventions and adherence. Chronic Wound Care Manag Res. 2015;2:11-21.

14. Pinto NR, Ubilla M, Zamora Y, Del Rio V, Dohan DM, Quirynen M. Leucocyte-and platelet-rich fibrin (L-PRF) as a regenerative medicine strategy for the treatment of refractory leg ulcers: a prospective cohort study. Platelets. 2018;29(5):468-475. doi:10.1080/ 09537104.2017.1327654
15. Somani A, Rai R. Comparison of efficacy of autologous platelet-rich fibrin versus saline dressing in chronic venous leg ulcers: a randomized controlled trial. J Cutan Aesthet Surg. 2017;10(1):8-12.

16. O’Connell SM, Impeduglia T, Hessler K, Wang XJ, Carroll RJ, Dardik H. Autologous platelet-rich fibrin matrix as cell therapy in the healing of chronic lower-extremity ulcers. Wound Repair Regen. 2008;16(6):749-756.

\section{Publish your work in this journal}

The International Medical Case Reports Journal is an international, peer-reviewed open-access journal publishing original case reports from all medical specialties. Previously unpublished medical posters are also accepted relating to any area of clinical or preclinical science. Submissions should not normally exceed 2,000 words or 4 published pages including figures, diagrams and references. The manuscript management system is completely online and includes a very quick and fair peer-review system, which is all easy to use. Visit http://www.dovepress.com/testimonials.php to read real quotes from published authors. 